\title{
Patients' Concerns at Their Admission in Hospital and Its Related Factors in Kermanshah, Iran
}

\author{
Soraya Siabani ${ }^{1,2,3}{ }^{\circledR}$, Leila Solouki $^{3^{*}}$, Afshin Almasi $^{3^{\circledR}}$, Sina Siabani $^{{ }^{\circledR}}$, Motahareh Khaledi $^{\circledR}$, Elaheh $^{\circledR}$ \\ Sepehri $^{{ }^{\circledR}}$, Maryam Almasi ${ }^{\circledR}$ \\ ${ }^{1}$ Public Health School, Kermanshah University of Medical Sciences, Kermanshah, Iran. \\ ${ }^{2}$ Faculty of Health, University of Technology Sydney, New South Wales, Australia. \\ ${ }^{3}$ Department of Biostatistics, School of Health, Kermanshah University of Medical Sciences, Kermanshah, Iran.
}

\begin{abstract}
Background: One of the critical factors affecting patients' outcomes is their concerns about different issues during their admission to the hospital. Clarifying these concerns and providing appropriate approaches could improve the quality of care, result in better outcomes, and reduce treatment costs. The present study aimed to investigate patients' concerns during hospitalization, and the likely related factors of the educational hospitals in Kermanshah, western Iran.

Materials and Methods: This analytical-descriptive study included 600 adult patients selected via a multi-stage sampling method and admitted to all four educational hospitals affiliated to Kermanshah University of Medical Sciences )KUMS) in 2016. Required data were collected using a survey with 15 questions on demographic information, current disease, medical records, and a researcherdeveloped questionnaire on factors causing concern in the Likert scale.

Results: Of 600 patients who participated in the survey, 336 (56\%) were female and 486 )81\%) were married. The most frequent concerns were the length of admission, failure in treatment or recovery, and hospital costs, respectively. The length of hospital stay, income, and level of education were significantly associated with the concern scores. Also, there was a significant difference between concern score distributions in groups with a definite diagnosis of illnesses $(P<0.05)$.

Conclusion: The results of this study suggested a correlation between variables such as education, income, the final diagnosis of a sickness, and the concern level of admitted patients. Our findings could help managers and hospital administrators better understand the concerns of admitted patients and find solutions to remove them.

Keywords: Hospitalization, Patient satisfaction, Quality of care, Health system, Patients' concerns
\end{abstract}

\author{
*Correspondence to \\ Leila Solouki, \\ Department of Biostatistics, \\ School of Health, \\ Kermanshah University \\ of Medical Sciences, \\ Kermanshah, Iran \\ Tel: +988335262052, \\ Email: I_soloki68@yahoo. \\ com
}

Received: January 2, 2021, Accepted: February 27, 2021, ePublished: March 30, 2021

\section{Introduction}

Although concerns result in dissatisfaction of peoples, average levels of concern are almost advantageous as people keep plans for the future to remove their concerns; however, excessive and uncontrollable concerns can hurt people (1).

Research on concern is quite recent and, due to the lack of comprehensible studies on this issue, the content of concern is not clearly defined and there is no reliable measurement on it (2). In general, concern has been defined as an attempt to solve mental problems with unknown results and one or a few possible negative consequences (3). In another study, concern was defined as an attempt to solve a problem where the danger is constantly recurring and there is no solution. Generally speaking, theorists agree that concern is a cognitive concept that is uncontrollable, and potentially changeable to future events and disasters (3-5). The concern could be explained as being worried about the future and negative events which result in a negative and severe mental verbal reaction (6).

Sickness and hospitalization could be stressful experiences for patients and their families, and may cause various concerns about each event from admission to discharge (7). Most patients admitted to hospitals are afraid of being confronted with an unfamiliar hospital environment, surgery room, and ICU equipment (8). Also, they worry about surgical complications, less physical strength, lack of playing their roles and responsibilities in the family or community; and due to facing negative emotions associated with these factors, patients find themselves stressed and anxious (8-10). It is known that stress could be helpful in moderation (11), though severe stress and concern in patients may interrupt diagnosis procedure, and lead to incomplete and complicated therapeutic tasks. Furthermore, it may increase the

(C) 2021 The Author(s). This is an open access article distributed under the terms of the Creative Commons Attribution License (http:// creativecommons.org/licenses/by/4.0/), which permits unrestricted use, distribution, and reproduction in any medium, provided the original work is properly cited. 
need for sedative medications and their complications (12), which can cause further problems. These concerns and anxieties create a defective cycle for the patient and increase the time of hospitalization, frequent visits to the hospital, and higher rates of in-hospital mortality, and even after discharge (4). Illness is not the only reason for concern in patients admitted to the hospital; therefore, concern and stress are not limited to anxiety disorders or diseases such as cancers $(13,14)$.

Various studies reported different causes for concern and anxiety in patients, including ignoring patients' physical and psychological needs (7), facing diagnostic procedures (15), lack of effective remedies to recover, lack of empathy of nurses, waiting for services (16), lack of information on medical procedures, and fear of pain during diagnostic treatments (17). It is important to control high concerns during examinations, since the concern may increase the duration of treatment and increase the possibility of side effects (18). There are no definite borders for the concern and it is not limited to patients with anxiety disorders (14) or cancer (13). The concerns in patients with heart failure are similar to those reported by cancer patients. $(19,20)$. Knowing the major concerns of patients admitted to hospitals can lead to a better understanding of the problems related to hospitalization, as well as the personal and family problems influencing their recovery process. Therefore, it is essential to develop effective interventions to reduce stress factors and modify the influence of this experience on patients and, as a result, facilitate the improvement of patients $(21,22)$. Accordingly, the present study addressed the types of concerns and the associated factors patients face during admission to hospitals.

\section{Materials and Methods}

This descriptive-analytic study was conducted on adult patients admitted to different educational hospitals affiliated to Kermanshah University of Medical Sciences, Iran in 2016-2017. The number of hospitalized patients was the criterion to calculate the share of each hospital, and random multi-stage sampling was used to select the samples.

Inclusion criteria were being over 18 years old, speaking Persian or Kurdish, having a stable physical condition, having mental health certified by a nurse at the hospital, and written consent to participate in the study.

\section{Participants}

Participants included all patients admitted to Imam Ali, Imam Khomeini, Taleghani, and Motazedi hospitals in Kermanshah, Iran . Using a multi-stage sampling method (stratified and then random sampling in each category), a total of 600 patients admitted to different departments of the hospitals were chosen as the participants. The share of each hospital was calculated according to the number of patients admitted to that hospital, and then the name and location of the participants were extracted from the admission list of patients by simple random sampling.

\section{Data Collection}

A socio-demographic questionnaire was used to gather the required data including demographic information, current disease, and medical history. A 27item researcher-developed questionnaire was used to collect the required data based on a 5-point Likert scale ( $1=$ strongly disagree to $5=$ strongly agree). The initial framework of the questionnaire was prepared using the contents of several studies in this field (23-26). The questionnaire was required to check patients' concerns about hospital expenses, family concerns, education and occupation concerns, complete treatment and recovery, concern about unfamiliar hospital environments, concern about medical services, and concern about diagnostic procedures. The validity of the content of the questionnaire was evaluated by consulting six experts in this field and applying the viewpoints in the pilot study. The reliability of the questionnaire was also measured using Cronbach's alpha coefficient (0.81). Descriptive and inferential statistics including mean, median, standard deviation, skewness, Kruskal-Wallis statistical tests, and Mann-Whitney test were used to analyze the data at statistical significance level $P<0.05$. furthermore, SPSS software version 21 was used to analyze the data.

After obtaining the required permissions from the Ethics Committee of KUMS, explaining the purpose of the research, and getting a consent letter from all subjects, the participants were requested to complete the questionnaire.

\section{Results}

In this study, out of 600 patients admitted to four educational hospitals in Kermanshah, Iran 336 (56\%) were female, $486(81 \%)$ were married, 72 (12\%) were single, and $42(7 \%)$ were divorced/widowed (Table 1). Also, $337(81 \%)$ of the patients were hospitalized in the surgical wards) gynecology, orthopedics, and general surgery), $101(16.8 \%)$ were in the general ward, and 13 (2. $2 \%$ ) were in the neurology ward. The final diagnosis of the disease was as follows: $132(21.3 \%)$ with respiratory heart disease, 98 (16\%) with internal problems, $12(2 \%)$ with psychiatric disorders, 53 (8.7) with cancer, 53 (8.3\%) with the urinary-genital system, and 86 (14\%) with trauma (Table 1).

Based on the results of the Kruskal-Wallis test, the distribution of concern scores was different in different educational groups $(P=0.012)$. Limit comparison tests (binary) found women to be more concerned than men $(P=0.83)$. Also, divorced/widowed showed to be more concerned than other groups $(P=0.93)$. It was shown that the concern score was associated with educational level, so that illiterate patients reported the highest concern $(P=0.043)$. The concern scores were higher 
Table 1. Distribution of Demographic Characteristics

\begin{tabular}{|c|c|c|c|}
\hline Characteristics & & Frequency & Percent \\
\hline \multirow{2}{*}{ Gender } & Female & 336 & 56 \\
\hline & Male & 264 & 44 \\
\hline \multirow{3}{*}{ Marital status } & Single & 72 & 12 \\
\hline & Married & 486 & 81 \\
\hline & Widow/Divorced & 42 & 7 \\
\hline \multirow{4}{*}{ Education } & Illiterate & 86 & 14.3 \\
\hline & High school & 261 & 43.5 \\
\hline & Diploma & 147 & 24.6 \\
\hline & Collage degree & 106 & 17.6 \\
\hline \multirow{9}{*}{ occupation } & Jobless & 40 & 6.7 \\
\hline & Student & 28 & 4.6 \\
\hline & Employed & 36 & 6 \\
\hline & Shop keeper & 25 & 4.2 \\
\hline & Worker & 21 & 3.5 \\
\hline & Farmer & 21 & 3.5 \\
\hline & Housekeeper & 264 & 44 \\
\hline & Self-employed & 125 & 20.8 \\
\hline & Retired & 40 & 6.7 \\
\hline \multirow{3}{*}{ Family role } & Father & 226 & 37.7 \\
\hline & Mother & 300 & 50 \\
\hline & Child & 74 & 12.3 \\
\hline \multirow{4}{*}{ Income } & $<\$ 100$ & 57 & 9.5 \\
\hline & 100 to $\$ 200$ & 230 & 38.3 \\
\hline & 200 to $\$ 300$ & 232 & 38.7 \\
\hline & Over $\$ 300$ & 81 & 13.5 \\
\hline \multirow{4}{*}{ Insurance } & Governmental & 305 & 50.8 \\
\hline & Social & 249 & 41.6 \\
\hline & Welfare & 20 & 3.3 \\
\hline & No insurance & 26 & 4.3 \\
\hline \multirow{7}{*}{$\begin{array}{l}\text { Past medical } \\
\text { history }\end{array}$} & Cardio-respiratory & 84 & 14 \\
\hline & Internal & 27 & 4.5 \\
\hline & Neurology and psychiatry & 13 & 2.2 \\
\hline & Cancer & 5 & 0.8 \\
\hline & Genitourinary & 6 & 1 \\
\hline & Missing & 397 & 66.2 \\
\hline & Others & 68 & 11.3 \\
\hline \multirow{3}{*}{ Unit } & Surgery & 337 & 81 \\
\hline & Internal & 101 & 16.8 \\
\hline & Neurology & 13 & 2.2 \\
\hline \multirow{7}{*}{ Current disease } & Cardio-respiratory & 132 & 22 \\
\hline & Internal & 98 & 16.4 \\
\hline & Neurology and psychiatry & 12 & 2 \\
\hline & Cancer & 53 & 8.8 \\
\hline & Genitourinary & 53 & 8.8 \\
\hline & Trauma & 86 & 14.3 \\
\hline & Others & 166 & 27.7 \\
\hline
\end{tabular}

\begin{tabular}{llcc} 
& $<1$ week & 335 & 55.8 \\
Length of & $10-7$ days & 201 & 33.5 \\
hospitalization & $30-10$ days & 56 & 9.3 \\
& Over a month & 8 & 1.3 \\
\hline & Cardio-respiratory & 128 & 31.3 \\
& Internal & 96 & 16 \\
The final diagnosis & Neurology and psychiatry & 12 & 2 \\
& Cancer disease & 52 & 8.7 \\
& Genitourinary & 50 & 8.3 \\
& Trauma & 84 & 14 \\
& Others & 178 & 29.7 \\
\hline
\end{tabular}

among workers, farmers, and housewives, respectively $(P=0.230)$. Regarding income (less than $\$ 100$, between 100 to $\$ 200$, between 200 to $\$ 300$, over $\$ 300$ ), it was observed that people with lower incomes had higher concern scores $(P<0.001)$. According to insurance status, patients with welfare insurance had higher concern scores than other groups $(P=0.073)$.

Also, regarding the length of admission in the hospital, those admitted less than a week showed lower concern compared to those hospitalized for more than a week $(P<0.001)$. There was a significant difference in the distribution of the concern scores for the groups with the final diagnosis of disease $(P<0.001)$, so that group 7 (other diseases) showed significantly lower levels of concern compared to the third )neurology) and fourth groups (cancer) (Table 2).

The results of the concern scores obtained from the questionnaire suggested that the highest concern scores were related to the following items: uncertainty about the duration of hospitalization ( concern about unsuccessful treatment and total recovery (score=1333, M=2.22), concern about the cost of the hospital (score=1251, M=1.89), concern about being in an unfamiliar environment in hospitals (score $=1136$, $\mathrm{M}=1.89$ ), and future re-admission )score $=1111, \mathrm{M}=1.85$ ).

\section{Discussion}

The present study sought to investigate the determinants of concern and its related factors in patients admitted to different wards of educational hospitals of Kermanshah, Iran. Based on the analysis of patients' information on a researcher-developed questionnaire, the present study suggested a significant relationship between variables of income rates, education, length of admission in the hospital, and final diagnosis of the disease with the patient's concern score. Results from the present study were consistent with the following studies on the variables under study and the concern scores.

A cross-sectional descriptive study investigated 130 patients with heart failure and reported a significant relationship between age the final diagnosis of disease 
Table 2. Distribution of Patients' Concern Score by Personal Characteristics

\begin{tabular}{|c|c|c|c|c|c|}
\hline Characteristics & & Mean & Median & SD & $P$ \\
\hline \multirow{2}{*}{ Gender } & Female & 31.98 & 30 & 17.05 & \multirow{2}{*}{0.83} \\
\hline & Male & 32.32 & 30 & 16.57 & \\
\hline \multirow{3}{*}{ Marital status } & Single & 33.26 & 27 & 19.32 & \multirow{3}{*}{0.92} \\
\hline & Married & 31.81 & 30 & 16.71 & \\
\hline & Divorced/Widow & 33.87 & 33.5 & 13.46 & \\
\hline \multirow{4}{*}{ Education } & Illiterate & 34 & 32 & 18.47 & \multirow{4}{*}{0.012} \\
\hline & High school & 33.65 & 32 & 15.73 & \\
\hline & Graduate & 29.84 & 28 & 17.21 & \\
\hline & Collage degree & 30.04 & 27 & 17.17 & \\
\hline \multirow{9}{*}{ Occupation } & Jobless & 32.57 & 28.5 & 18 & \multirow{9}{*}{0.230} \\
\hline & Student & 28.64 & 24.5 & 16.04 & \\
\hline & Employed & 31.61 & 30.5 & 18.16 & \\
\hline & Shop keeper & 34.68 & 29 & 18.62 & \\
\hline & Worker & 40.52 & 37 & 19.25 & \\
\hline & Farmer & 39.95 & 36 & 19.40 & \\
\hline & Housekeeper & 39.14 & 31 & 17.01 & \\
\hline & Self-employed & 30.55 & 30 & 14.80 & \\
\hline & Retired & 29.37 & 228.5 & 14.45 & \\
\hline \multirow{3}{*}{ Family role } & Father & 32.56 & 30 & 16.12 & \multirow{3}{*}{0.745} \\
\hline & Mother & 31.45 & 30 & 16.37 & \\
\hline & Child & 33.58 & 27 & 19.28 & \\
\hline \multirow{4}{*}{ Income } & $<\$ 100$ & 41.77 & 39 & 18 & \multirow{4}{*}{0.000} \\
\hline & 100 to $\$ 200$ & 31.99 & 30 & 17.08 & \\
\hline & 200 to $\$ 300$ & 30.30 & 29 & 15.41 & \\
\hline & Over $\$ 300$ & 31.01 & 30 & 17.22 & \\
\hline \multirow{4}{*}{ Insurance } & Governmental & 31.5 & 30 & 16.76 & \multirow{4}{*}{0.073} \\
\hline & Social & 31.84 & 29 & 17.20 & \\
\hline & Welfare & 40.80 & 39.5 & 13.82 & \\
\hline & No insurance & 35.9 & 36 & 14.55 & \\
\hline \multirow{7}{*}{$\begin{array}{l}\text { Past medical } \\
\text { history }\end{array}$} & Cardio-respiratory & 35.66 & 30.5 & 18.17 & \multirow{7}{*}{0.148} \\
\hline & Internal & 33.33 & 34 & 15.14 & \\
\hline & $\begin{array}{l}\text { Neurology and } \\
\text { psychiatry }\end{array}$ & 27.53 & 27 & 10.27 & \\
\hline & Cancer & 41.6 & 33 & 27.72 & \\
\hline & Genitourinary & 48.33 & 51.5 & 20.39 & \\
\hline & Missing & 31.26 & 30 & 16.70 & \\
\hline & Others & 31.14 & 30.5 & 15.32 & \\
\hline \multirow{3}{*}{ Ward } & Surgery & 31.54 & 30 & 17.28 & \multirow{3}{*}{0.151} \\
\hline & Internal & 32.57 & 29.5 & 16.32 & \\
\hline & Neurology & 39 & 36 & 13.68 & \\
\hline \multirow{7}{*}{ Current disease } & Cardio-respiratory & 33.56 & 30 & 17.66 & \multirow{7}{*}{0.000} \\
\hline & Internal & 33.47 & 31 & 14.01 & \\
\hline & $\begin{array}{l}\text { Neurology and } \\
\text { psychiatry }\end{array}$ & 43.08 & 39 & 10.59 & \\
\hline & Cancer & 38.28 & 37 & 19.64 & \\
\hline & Genitourinary & 29.90 & 31 & 15.32 & \\
\hline & Trauma & 33.15 & 30 & 16.72 & \\
\hline & Others & 27.63 & 26 & 16.5 & \\
\hline
\end{tabular}

\begin{tabular}{llcccc}
\hline & $<$ A week & 28.39 & 27 & 17.08 & \\
Length of & 10-7 days & 34.66 & 33 & 14.36 & \\
hospitalization & $30-10$ days & 40.17 & 41.5 & 17.56 & 0.000 \\
& Over a month & 45.12 & 49 & 25.11 & \\
\hline & Cardio-respiratory & 3.71 & 30 & 17.74 & \\
& Internal & 33.27 & 31 & 14.41 & \\
$\begin{array}{l}\text { The final } \\
\text { diagnosis of } \\
\text { disease }\end{array}$ & Neurology and & 43.08 & 39 & 10.59 & \\
& Canchiatry & 38.92 & 37.5 & 18.27 & 0.000 \\
& Genitourinary & 30.12 & 31 & 15.48 & \\
& Trauma & 32.69 & 30 & 16.11 & \\
& Others & 27.97 & 26.9 & 16.35 & \\
\hline
\end{tabular}

and length of hospital admission with concern score on future (27). Results from the present study suggested a significant difference between the concern scores among the diagnostically categorized groups so that patients in cancer and neurology groups showed higher levels of concern compared to other groups. Also, patients hospitalized for less than a week were less concerned in comparison to patients admitted to hospitals for a longer period. It could be inferred that since more serious health issues need longer health care, patients with severe health problems have higher concern scores.

Another study compared the concern and depression among 300 patients with coronary artery disease admitted to hospitals patients using the standardized Hospital Anxiety and Depression Scale (HADS). Results from the study showed a high prevalence of concern and depression among the patients (28). The current study reported a significant difference in the concern scores among the groups categorized with the final disease diagnosis and suggested higher levels of concern among cancer and neurology groups compared to other groups. In addition, the results reported higher levels of concern in groups suffering from more serious health problems.

Results of a cross-sectional descriptive study on 218 family members of 130 hospitalized patients reported a poor economic status of the families regarding hospital costs and role changes as effective factors on the increase of the anxiety and concern among families (29). The present study also suggested higher concern scores among patients with lower income levels and poor economic conditions compared to others. This condition may result from the poor work condition in Iran where better-paid jobs need higher education at the governmental level. However, the role's change was not found significant in the concern scores in the present study.

Also, a cross-sectional study to estimate patient's safety, satisfaction, and quality of hospital care on 61168 nurses and 130000 patients in 12 European countries and the United States reported dissatisfaction of quality of hospital care in all countries and suggested improving the hospital's working environment as a relatively low-cost strategy to 
increase safety and quality of hospital care and, as the result, patients' satisfaction (30). Although the concern scores in the present study generally showed patients' low levels of concern about admission to hospitals, findings from our study were strongly consistent with the results above and clarified the linear relationship between the concern score and length of admission, concern about unsuccessful treatment and total recovery, unfamiliar environments in hospital and, last but not least, concern about re-admission. Therefore, it could be understood that increasing the quality of hospital care and patients' satisfaction may help reduce the patients' concerns during hospital admission.

One of the main limitations of this study was the reluctance of patients to participate in completing questionnaires due to the severity of the disease and pain. To resolve this problem, severely ill patients were excluded from the study because they might give unrealistic answers or not answer all questions due to fear of confrontation with the staff. To reduce this limitation, the questioners were trained to assure the confidentiality of patients' information.

\section{Conclusion}

The results of the present study indicated a significant relationship between the variables of literacy, average income, length of admission, the final diagnosis of disease, and the level of concern among patients admitted to hospitals, which could help better understand the problems associated with hospitalization experience and introduce effective interventions to control influential factors of the concern. The findings of this study could offer practical suggestions to reduce the patients' concerns while admission to hospitals. That includes training and enhancing the medical team's therapeutic capabilities based on patients' needs, effective communication with patients to support them, reducing stress factors to facilitate the recovery process and improve disability and mortality and reduce treatment and patient costs.

\section{Conflict of Interests Disclosure}

None.

\section{Acknowledgments}

The researchers appreciate all the educational hospitals in Kermanshah, Iran for their collaboration. We also thank all patients who participated in this study.

\section{Ethical Statement}

The Ethics Committee of Kermanshah University of Medical Sciences approved the study )code: IR.KUMS. REC.1395.246).

\section{Authors' Contributions}

SS supervised and managed the study. LS was statistical analyzer and Article writer. AA was the statistical consultant for the project. E S, MA and M Kh collected information.

\section{Funding/Support}

This study was funded by Kermanshah University of Medical
Sciences, Iran.

\section{Informed Consent}

Informed consent was obtained from all the participants.

\section{References}

1. Davey GCL, Hampton J, Farrell J, Davidson S. Some characteristics of worrying: evidence for worrying and anxiety as separate constructs. Pers Individ Dif. 1992;13(2):133-47. doi: 10.1016/0191-8869(92)90036-o.

2. Macher D, Papousek I, Ruggeri K, Paechter M. Statistics anxiety and performance: blessings in disguise. Front Psychol. 2015;6:1116. doi: 10.3389/fpsyg.2015.01116.

3. Borkovec TD, Robinson E, Pruzinsky T, DePree JA. Preliminary exploration of worry: some characteristics and processes. Behav Res Ther. 1983;21(1):9-16. doi: 10.1016/00057967)83)90121-3.

4. MacLeod AK, Williams JM, Bekerian DA. Worry is reasonable: the role of explanations in pessimism about future personal events. J Abnorm Psychol. 1991;100(4):478-86. doi: 10.1037//0021-843x.100.4.478.

5. Mathews A. Why worry? the cognitive function of anxiety. Behav Res Ther. 1990;28(6):455-68. doi: 10.1016/00057967)90)90132-3.

6. Davey GC, Wells A. Worry and its Psychological Disorders: Theory, Assessment and Treatment. John Wiley \& Sons; 2006.

7. Shafipour V, Mohammadi E, Ahmadi F. Experiences of open heart surgery patients from admission to discharge: a qualitative study. Iran J Crit Care Nurs. 2013;6(1):1-10.

8. Karlsson AK, Johansson M, Lidell E. Fragility--the price of renewed life. Patients experiences of open heart surgery. Eur J Cardiovasc Nurs. 2005;4(4):290-7. doi: 10.1016/j. ejcnurse.2005.03.009.

9. Ivarsson B, Larsson S, Sjöberg T. Patients' experiences of support while waiting for cardiac surgery. A critical incident technique analysis. Eur J Cardiovasc Nurs. 2004;3(2):183-91. doi: 10.1016/j.ejcnurse.2004.03.001.

10. Koivula M, Paunonen-IImonen M, Tarkka MT, Tarkka M, Laippala P. Social support and its relation to fear and anxiety in patients awaiting coronary artery bypass grafting. J Clin Nurs. 2002;11(5):622-33. doi: 10.1046/j.1365-2702.2002.00653.x.

11. Frasure-Smith $\mathrm{N}$, Lespérance $\mathrm{F}$. Depression and anxiety as predictors of 2-year cardiac events in patients with stable coronary artery disease. Arch Gen Psychiatry. 2008;65(1):6271. doi: 10.1001/archgenpsychiatry.2007.4.

12. El-Hassan H, McKeown K, Muller AF. Clinical trial: music reduces anxiety levels in patients attending for endoscopy. Aliment Pharmacol Ther. 2009;30(7):718-24. doi: 10.1111/j.1365-2036.2009.04091.x.

13. Chochinov HM, Hack T, McClement S, Kristjanson L, Harlos M. Dignity in the terminally ill: a developing empirical model. Soc Sci Med. 2002;54(3):433-43. doi: 10.1016/ s0277-9536(01)00084-3.

14. Khawaja NG, Chapman D. Cognitive predictors of worry in a non-clinical population. Clin Psychol. 2007;11(1):24-32. doi: 10.1080/13284200601151778.

15. Delewi R, Vlastra W, Rohling WJ, Wagenaar TC, Zwemstra $M$, Meesterman MG, et al. Anxiety levels of patients undergoing coronary procedures in the catheterization laboratory. Int J Cardiol. 2017;228:926-30. doi: 10.1016/j. ijcard.2016.11.043.

16. Rejeh N, Heravi-Karimooi M, Foroughan M. An exploration into the lived experiences of the hospitalized older women of sleep phenomenon and its disturbance: a qualitative study. Daneshvar Medicine. 2010;17(86):19-26.

17. Kutlutürkan S, Görgülü U, Fesci $H$, Karavelioglu A. The 
effects of providing pre-gastrointestinal endoscopy written educational material on patients' anxiety: a randomised controlled trial. Int J Nurs Stud. 2010;47(9):1066-73. doi: 10.1016/j.ijnurstu.2010.01.007.

18. van Zuuren FJ, Grypdonck M, Crevits E, Vande Walle C, Defloor T. The effect of an information brochure on patients undergoing gastrointestinal endoscopy: a randomized controlled study. Patient Educ Couns. 2006;64(1-3):173-82. doi: 10.1016/j.pec.2005.12.014.

19. Mcllvennan CK, Allen LA. Palliative care in patients with heart failure. BMJ. 2016;353:i1010. doi: 10.1136/bmj.i1010.

20. Ryan M, Farrelly M. Living with an unfixable heart: a qualitative study exploring the experience of living with advanced heart failure. Eur J Cardiovasc Nurs. 2009;8(3):22331. doi: 10.1016/j.ejcnurse.2009.02.005.

21. Andenaes R, Kalfoss MH, Wahl A. Psychological distress and quality of life in hospitalized patients with chronic obstructive pulmonary disease. J Adv Nurs. 2004;46)5):523-30. doi: 10.1111/j.1365-2648.2004.03026.x.

22. Oyetunde MO, Ojo OO, Ojewale LY. Nurses' attitude towards the care of the elderly: implications for gerontological nursing training. J Nurs Educ Pract. 2013;3(7):150-8. doi: 10.5430/ jnep.v3n7p150.

23. Garbutt JM, Leege E, Sterkel R, Gentry S, Wallendorf $M$, Strunk RC. What are parents worried about? health problems and health concerns for children. Clin Pediatr (Phila). 2012;51(9):840-7. doi: 10.1177/0009922812455093.

24. Gardiner C, Gott M, Small N, Payne S, Seamark D, Barnes $\mathrm{S}$, et al. Living with advanced chronic obstructive pulmonary disease: patients concerns regarding death and dying. Palliat Med. 2009;23)8):691-7. doi: 10.1177/0269216309107003.

25. Radiotis G, Roberts N, Czajkowska Z, Khanna M, Körner A. Nonmelanoma skin cancer: disease-specific quality-of-life concerns and distress. Oncol Nurs Forum. 2014;41(1):57-65. doi: 10.1188/14.onf.57-65.

26. Teng $\mathrm{CL}$, Jamin ZM, Kamaruddin NIM, Idris SA. Health beliefs, concerns and expectations of patients presenting with non-acute pain: a preliminary study from a government health clinic in Malaysia. Asia Pac Fam Med. 2003;2(1):23-6. doi: 10.1046/j.1444-1683.2003.00046.x.

27. Bagheri H, Yaghmaei F, Ashktorab T, Zayeri F. Psychometric properties of Illness Related Worries Questionnaire IRWQ) in heart failure patients. Iranian Journal of Psychiatric Nursing. 2014;2(1):23-33.

28. Ebadi A, Moradian ST, Feyzi F, Asiabi M. Comparison of hospital anxiety and depression among patients with coronary artery disease based on proposed treatment. Iran J Crit Care Nurs. 2011;4(2):97-102.

29. Rabie Siahkali S, Avazeh A, Eskandari F, Khalegh Doost Mohamadi T, Mazloom S, Paryad E. A survey on psychological and environmental factors on family anxiety of the hospitalized patients in intensive care units. Iran J Crit Care Nurs. 2011;3(4):171-6.

30. Aiken LH, Sermeus W, Van den Heede K, Sloane DM, Busse $\mathrm{R}$, McKee $\mathrm{M}$, et al. Patient safety, satisfaction, and quality of hospital care: cross sectional surveys of nurses and patients in 12 countries in Europe and the United States. BMJ. 2012;344:e1717. doi: 10.1136/bmj.e1717. 